\title{
Maternal body composition, HIV infection and other predictors of gestation length and birth size in Zimbabwe
}

\author{
Henrik Friis ${ }^{1}$, Exnevia Gomo ${ }^{2,3}$, Norman Nyazema ${ }^{4}$, Patricia Ndhlovu ${ }^{5}$, Henrik Krarup ${ }^{6}$, \\ Pernille Kæstel $^{7}$ and Kim Fleischer Michaelsen ${ }^{7}$ \\ ${ }^{1}$ Department of Epidemiology, Institute of Public Health, University of Copenhagen, Panum Institute, Blegdamsvej 3, \\ DK-2200 Copenhagen N, Denmark \\ ${ }^{2}$ Blair Research Laboratory, Ministry of Health, Harare, Zimbabwe \\ ${ }^{3}$ Department of Immunology, University of Zimbabwe, Harare, Zimbabwe \\ ${ }^{4}$ Department of Clinical Pharmacology, University of Zimbabwe, Harare, Zimbabwe \\ ${ }^{5}$ Department of Medical Laboratory Sciences, University of Zimbabwe, Harare, Zimbabwe \\ ${ }^{6}$ Department of Clinical Biochemistry, Aalborg University Hospital, Aalborg, Denmark \\ ${ }^{7}$ Department of Human Nutrition, Royal Veterinary and Agricultural University, Frederiksberg, Denmark
}

(Received 14 May 2004 - Revised 21 July 2004 - Accepted 5 August 2004)

\begin{abstract}
The role of maternal infections, nutritional status and obstetric history in low birth weight is not clear. Thus, the objective of the present study was to assess the effects of maternal HIV infection, nutritional status and obstetric history, and season of birth on gestation length and birth size. The study population was 1669 antenatal care attendees in Harare, Zimbabwe. A prospective cohort study was conducted as part of a randomised, controlled trial. Maternal anthropometry, age, gravidity, and HIV status and load were assessed in $22 \mathrm{nd}-35$ th weeks gestation. Outcomes were gestation length and birth size. Birth data were available from $1106(66.3 \%)$ women, of which 360 (32.5\%) had HIV infection. Mean gestation length was 39.1 weeks with $16.6 \%<37$ weeks, mean birth weight was $3030 \mathrm{~g}$ with $10.5 \%<2500 \mathrm{~g}$. Gestation length increased with age in primigravidae, but not multigravidae (interaction, $P=0.005$ ), and birth in the early dry season, low arm fat area, multiple pregnancies and maternal HIV load were negative predictors. Birth weight increased with maternal height, and birth in the late rainy and early dry season; primi-secundigravidity, low arm fat area, HIV load, multiple pregnancies and female sex were negative predictors. In conclusion, gestation length and birth weight decline with increasing maternal HIV load. In addition, season of birth, gravidity, maternal height and body fat mass, and infant sex are predictors of birth weight.
\end{abstract}

Pregnancy: HIV infection: Body composition: Gestation length: Birth size: Zimbabwe

Women in developing countries are exposed to inadequate dietary intake, frequent reproductive cycles, infectious diseases and hard physical work. In addition to detrimental effects on their own health, these conditions may be responsible for the high incidence of low birth weight in developing countries (de Onis et al. 1998). Low birth weight is a major determinant of child morbidity and mortality (Ashworth, 1998), and may even increase the risk of infectious and chronic diseases in adolescence and adulthood (Moore et al. 1999; Barker et al. 2001; McDade et al. 2001). Since both the determinants and effects of low birth weight depend on whether it is due to preterm delivery or intra-uterine growth retardation (Kramer, 2003), it is important to control for gestation length when studying low birth weight.

As part of a randomised, controlled multimicronutrient supplementation trial, we examined the role of maternal
HIV infection and anthropometry, obstetric history and season on gestation length and birth size, with an aim of contributing towards an improved understanding of the causes of low birth weight. Baseline data on micronutrient status (Friis et al. 2001a,b), body composition (Friis et al. $2002 b$ ) and HIV viral load (Friis et al. 2003) have previously been reported, as have data on the effect of multimicronutrient supplementation on gestation length and birth size (Friis et al. 2004).

\section{Subjects and methods}

Study area and population

The present study was conducted in the residential area of Mbare in Harare, Zimbabwe, in 1996-97 as part of a randomised, controlled multimicronutrient trial. Harare is 
$1500 \mathrm{~m}$ above sea level and has a tropical climate with mean daily minimum and maximum temperatures of 12 and $25^{\circ} \mathrm{C}$, respectively. There are four main seasons: early (June to August) and late (September to November) dry, and early (December to February) and late (March to May) rainy. The common diet is maize-meal porridge taken with vegetables and occasionally meat. Unemployment is very high in Mbare, especially among women, and most of those employed are general labourers. Malaria is not endemic in the study area because of the high altitude, but most women often return to their rural homes outside Harare, where malaria transmission may occur.

Women registering for antenatal care at the Edith Oppermann Maternity Hospital (EOMH) were informed about the present study, and those between 22 and 36 weeks gestation were offered inclusion. Women were informed about HIV testing and counselled before giving their written consent to participate. Counselling was provided by a nongovernmental organisation, AIDS Counseling Trust. HIV results were made available within 2 weeks, when those willing to know their results were post-test counselled. A questionnaire was administered, and a clinical examination and blood sampling were done. A research nurse obtained demographic data, and medical and obstetric history. Gestational age was calculated from the first day of the last menstruation, or estimated by fundus height.

Permission was obtained from the ethical and scientific committees of the Medical Research Council of Zimbabwe, Harare City Health Department and the Ministry of Health. The Danish Central Medical Ethics Committee also approved the present study. Women were pre-test counselled before giving written consent. The national Ministry of Health recommendations were adhered to when giving women information on breast-feeding. Women found sick during clinical examination were referred for treatment at the EOMH or Harare Central Hospital.

\section{Anthropometric examinations of the mother}

Clinical examination of the mother was done as part of antenatal care. Heights were measured to the nearest $0.1 \mathrm{~cm}$ and weights to the nearest $0.1 \mathrm{~kg}$, with the women barefooted and wearing light clothing. Mid-upper-arm circumference was measured to the nearest $0.1 \mathrm{~cm}$, and triceps skinfold thickness to the nearest $0.1 \mathrm{~mm}$ on the right arm. Based on arm circumference and triceps skinfold thickness, the arm muscle area and arm fat area were calculated, as described previously (Friis et al. 2002b).

\section{HIV infection and malaria}

Venous blood was collected between 09.00 and 12.00 hours at recruitment. Blood was collected in EDTA tubes $(5 \mathrm{ml})$ and in plain tubes $(5 \mathrm{ml})$. The samples were placed in ice-cooled insulated boxes immediately after collection and were delivered to the laboratory within $4 \mathrm{~h}$. Thick and thin blood slides were made for malaria parasitaemia. Serum was separated and stored in liquid $\mathrm{N}_{2}$ at $-196^{\circ} \mathrm{C}$ until tested for HIV. Samples found negative with the Genelavia Mixt (Sanofi, Marnes La Coquette, France) HIV-1/2 enzyme immuno assay kit were reported negative. Positive and indeterminate samples were further tested using the Recombigen HIV-1/2 (Cambridge Biotech Ltd., Galway, Republic of Ireland) enzyme immuno assay with different antigens from the Genelavia kit. Samples positive or indeterminate with the Recombigen kit were tested at the Department of Clinical Chemistry, Aalborg University Hospital, Denmark, using a modification of an in-house developed RT-PCR (Krarup et al. 1998).

\section{Birth records}

Infants delivered at the EOMH were weighed, and length and head circumference were measured, within $72 \mathrm{~h}$. The birth weight was determined to the nearest $0.01 \mathrm{~kg}$ using a Sohnle baby scale (Sohnle, Murrhardt, Germany). When study participants did not deliver at the EOMH or were not examined by the research team, routine birth records were used.

\section{Statistical analysis}

The distribution of the continuous outcome variables conformed to normality as assessed by normal probability plots. The two-sample $t$ test and the $\chi^{2}$ test were used to test for differences in means and proportions, respectively. The outcome variables were measurements of gestation length and birth size, i.e. birth weight, birth length and head circumference. Based on these variables, the ponderal index (birth weight $(\mathrm{kg}) /$ length $\left.(\mathrm{m})^{3}\right)$, preterm delivery (gestation length $<37$ weeks), birth weight $<2500 \mathrm{~g}$ and intra-uterine growth retardation-low birth weight (defined as gestation length $>37$ weeks and birth weight $<2500 \mathrm{~g}$ ) were computed. All singletons and the first-born of twin pregnancies were included in the analysis.

Multiple linear and logistic regression analyses were used to assess and estimate the statistical effects on gestation length and birth size of season of birth, maternal age and gravidity, height, arm muscle and fat area, malaria parasitaemia, HIV status and viral load. In addition, twin pregnancies and infant sex were also included. The effect of micronutrient supplementation was controlled for.

HIV-uninfected women were assigned an HIV load of 0 , before $\log _{10}(x+1)$ transformation. Continuous variables were subtracted from the mean value, to let the intercept reflect the mean of the outcome variable among women falling into all reference categories and with mean values of all continuous variables. Dummy variables were used to assess the statistical effect of categorical variables or continuous variables where the relationship was not linear. When doing so, missing values were included as a separate category. When interactions were identified, then terms were computed to allow estimation of the statistical effect of one of the variables separately for each level of the effect-modifying variable. Variables with $P<0 \cdot 10$ were retained in the models, but only reported as significant if $P<0.05$.

Residual analysis was performed by assessing normal plots, and by plotting standardised residuals against predicted values and continuous independent variables. 


\section{Results}

Birth records were available for $1106(66 \cdot 3 \%)$ of the 1669 women recruited. As seen in Table 1, there were no differences in age, anthropometric measurements, gestational age and HIV prevalence among the 1106 women on whom birth anthropometry data were available, compared with the 563 women on whom data were not available, but the proportion of primigravidae was higher. The analysis included $1094(98.8 \%)$ singletons and the first-born of twelve pairs of twins. Of these 1106 neonates, ten $(0.9 \%)$ were stillborn. Only twenty-two $(2.0 \%)$ of the 1106 deliveries were by caesarean section, mainly emergency sections due to pre-eclampsia or fetal distress. Mean gestation length was 39.1 weeks with $184(16.6 \%)<37$ weeks, mean birth weight was $3030 \mathrm{~g}$ with $116(10.5 \%)$ $<2500 \mathrm{~g}$ and $538(48.6 \%)<3000 \mathrm{~g}$, and sixty-six $(6.0 \%)$ were $<2500 \mathrm{~g}$, but $>37$ weeks (intra-uterine growth retardation-low birth weight).

\section{HIV infection, anthropometry and other predictors}

Of the 1106 mothers, 360 (32.5\%) had HIV infection and five $(0.5 \%)$ had malaria parasitaemia at inclusion. There were no differences between HIV-uninfected and -infected women in respect of stillbirths (six $(0.8 \%) v$. five $(1.5 \%)$; $P=0.38)$ and caesarean sections (seventeen $(2.4 \%) v$. five $(1.5 \%) ; P=0.31$ ) (data not shown). However, as seen in Table 2, children born to HIV-infected mothers were born after $0.4(95 \%$ CI $0.05,0.8)$ weeks shorter gestation, and had 88 (95\% CI 29, 147) g lower weight and 0.5 $(95 \%$ CI $0.2,0.9) \mathrm{cm}$ shorter length at birth compared with children of uninfected mothers, whereas there were no differences in ponderal index and head circumference. Similarly, maternal HIV infection was associated with a $46 \%$ (relative risk $1.46(95 \%$ CI 1.12, 1.91)) increased risk of preterm delivery, and a $74 \%$ (relative risk 1.74 (95\% CI 1.23, 2.46)) increased risk of birth weight $<2500 \mathrm{~g}$. The risk of birth weight $<3000 \mathrm{~g}$ and intra-uterine growth retardation-low birth weight was not significantly increased (Table 3 ).

The effects of HIV infection and other predictors on gestation length and birth size were assessed in multiple linear and logistic regression analysis, and are shown in Tables 4-8.

\section{Gestation length}

An interaction was revealed between age and gravidity $(P=0.005)$ on gestation length. The interaction identified was due to an increasing gestational age at delivery with increasing age in primigravidae $(0.14$ (95\% CI $0 \cdot 1,0.2)$; $P=0.002)$, but neither in gravidae $2(0.05(95 \% \mathrm{CI}-0.06$, $0.15) ; \quad P=0.37), 3(-0.006 \quad(95 \%$ CI $-0.10,0.09)$; $P=0.91)$ nor $4+(-0.02(95 \%$ CI $-0.11,0.08) ; P=0.71)$. In Table 4 , the effect of age was therefore estimated separately for primigravidae and gravidae $2+$. Since the difference in length of gestation between gravidae 1 and $2+$ thus depends on age of comparison, it was estimated at mean

Table 1. Baseline characteristics of the 1106 women on whom birth-weight data were available compared with the 563 not included in the analyses $(n 1669)$

(Mean values or prevalences and $95 \%$ confidence intervals)

\begin{tabular}{|c|c|c|c|c|c|}
\hline & \multicolumn{2}{|c|}{ Included (n 1106) } & \multicolumn{2}{|c|}{ Not included ( $n$ 563) } & \multirow[b]{2}{*}{$P$} \\
\hline & Mean & $95 \% \mathrm{Cl}$ & Mean & $95 \% \mathrm{Cl}$ & \\
\hline Age (years) & $24 \cdot 2$ & $23.9,24.5$ & $24 \cdot 3$ & $23 \cdot 8,24 \cdot 8$ & 0.70 \\
\hline \multicolumn{6}{|l|}{ Season of enrolment (\%) } \\
\hline Early rainy & 18 & 15,20 & 19 & 16,22 & 0.58 \\
\hline Late rainy & 13 & 11,15 & 17 & 14,21 & 0.01 \\
\hline Early dry & 40 & 37,43 & 39 & 35,43 & 0.62 \\
\hline Late dry & 30 & 27,33 & 25 & 22,29 & 0.04 \\
\hline Gestational age (weeks) & 29.2 & $29 \cdot 0,29 \cdot 4$ & 28.9 & $28 \cdot 6,29 \cdot 2$ & 0.07 \\
\hline Primigravidae (\%) & 37 & 35,40 & 45 & 41,49 & 0.004 \\
\hline BMI $\left(\mathrm{kg} / \mathrm{m}^{2}\right)$ & $25 \cdot 1$ & $24 \cdot 8,25 \cdot 3$ & 24.9 & $24 \cdot 6,25 \cdot 2$ & 0.25 \\
\hline $\mathrm{Hb}(\mathrm{g} / \mathrm{l})$ & $115 \cdot 3$ & $114 \cdot 5,116 \cdot 1$ & 114.5 & $113 \cdot 3,115 \cdot 8$ & 0.27 \\
\hline HIV-1 (\%) & 33 & 30,36 & 30 & 26,34 & 0.19 \\
\hline
\end{tabular}

Table 2. Effects of maternal HIV infection on gestation length and birth weight, length and head circumference of 1106 infants by maternal HIV status*

(Mean values or mean differences and $95 \%$ confidence intervals)

\begin{tabular}{lccccc}
\hline & HIV uninfected $(n$ 725) & HIV infected $(n 360)$ & Difference & $95 \% \mathrm{Cl}$ & $P$ \\
\hline Gestation length (weeks) & 39.3 & 38.8 & 0.4 & $0.05,0.8$ & 0.02 \\
Birth weight $(\mathrm{g})$ & 3057 & 2969 & 88 & 29,147 & 0.005 \\
Birth length $(\mathrm{cm}) \dagger$ & 48.8 & 48.3 & 0.5 & $0.2,0.9$ & 0.002 \\
Ponderal index $\left(\mathrm{kg} / \mathrm{m}^{3}\right) \dagger$ & 26.4 & 26.5 & -0.04 & $-0.7,0.6$ & 0.91 \\
Head circumference $(\mathrm{cm}) \ddagger$ & 33.7 & 33.6 & 0.07 & $-0.2,0.3$ & 0.56 \\
\hline
\end{tabular}

${ }^{*} \mathrm{HIV}$ status was indeterminate in twenty-one women.

$\dagger n 986$ For birth length and ponderal index (birth weight $(\mathrm{kg}) /$ length $\left.(\mathrm{m})^{3}\right)$.

$\ddagger n 1007$ For head circumference. 
Table 3. Effects of maternal HIV infection on preterm delivery, birth weight $<2500$ and $<3000 \mathrm{~g}$, and intra-uterine growth retardation-low birth weight (IUGR-LBW) of 1106 infants

(Prevalences, relative risks and $95 \%$ confidence intervals)

\begin{tabular}{|c|c|c|c|c|c|c|c|}
\hline & \multicolumn{2}{|c|}{$\begin{array}{l}\text { HIV uninfected } \\
\quad(n 725)\end{array}$} & \multicolumn{2}{|c|}{$\begin{array}{l}\text { HIV infected } \\
\quad(n 360)\end{array}$} & \multirow[b]{2}{*}{ Relative risk } & \multirow[b]{2}{*}{$95 \% \mathrm{Cl}$} & \multirow[b]{2}{*}{$P$} \\
\hline & $\%$ & $n$ & $\%$ & $n$ & & & \\
\hline Preterm delivery $<37$ weeks & 14.4 & 104 & $21 \cdot 1$ & 76 & 1.46 & $1.12,1.91$ & 0.005 \\
\hline Birth weight $<2500 \mathrm{~g}$ & 8.4 & 61 & $14 \cdot 7$ & 53 & 1.74 & $1.23,2.46$ & 0.001 \\
\hline$<3000 \mathrm{~g}$ & $47 \cdot 0$ & 341 & $52 \cdot 2$ & 188 & 1.10 & $0.97,1.25$ & 0.11 \\
\hline IUGR-LBW* ${ }^{*}$ & $5 \cdot 3$ & 38 & 7.5 & 27 & 1.42 & $0.88,2.29$ & 0.17 \\
\hline
\end{tabular}

* IUGR-LBW is defined as gestation length $>37$ weeks and birth weight $<2500 \mathrm{~g}$.

age 24 years. As seen, the mean gestation length was 0.6 weeks longer in infants of primigravidae compared with gravidae $2+$. At age 32 years, the difference was 1.7 (95\% CI 0.6, 2.9) weeks (data not shown).

Season of birth was a predictor, as those born in the early dry season had a $2.3(95 \%$ CI $1.7,2 \cdot 8)$ weeks shorter gestation than those born in the late rainy season. Maternal arm fat area was also a strong predictor of gestation length. The adjusted $R^{2}$ was highest with arm fat area included as dummy variables, using values above the mean of $20 \mathrm{~cm}^{2}$ as reference. Mothers with arm fat areas $<10 \mathrm{~cm}^{2}$ and between 10 and $20 \mathrm{~cm}^{2}$ delivered after 1.5 and 0.6 weeks, respectively, shorter gestation. In contrast, there was no difference in gestation length of women with arm fat areas between 20 to $30 \mathrm{~cm}^{2}$ and $>30 \mathrm{~cm}^{2}$ (data not shown). Twin pregnancies were associated with 1.8 weeks shorter gestation, but these estimates were based on only twelve pairs of twins. Sex of the offspring was

Table 4. Predictors of estimated gestation length (weeks) in 1106 infants* (Regression coefficients (B) and $95 \%$ confidence intervals)

\begin{tabular}{|c|c|c|c|}
\hline Variables & $B$ & $95 \% \mathrm{Cl}$ & $P$ \\
\hline \multicolumn{4}{|l|}{ Season of birth } \\
\hline Early dry (n 274) & $-2 \cdot 3$ & $-2 \cdot 8,-1 \cdot 7$ & $<0.0000$ \\
\hline Late dry (n 379) & -0.6 & $-1 \cdot 2,-0.1$ & 0.01 \\
\hline Early rain (n 291) & -0.8 & $-1 \cdot 3,-0.3$ & 0.003 \\
\hline \multicolumn{4}{|l|}{ Arm fat area $\left(\mathrm{cm}^{2}\right) \dagger$} \\
\hline$<10(n 52)$ & -1.5 & $-2.3,-0.7$ & 0.0002 \\
\hline $10-20(n 585)$ & -0.6 & $-0.9,-0.3$ & 0.0004 \\
\hline \multicolumn{4}{|l|}{ Age (years) $\ddagger$} \\
\hline In gravida 1 (n 411) & 0.14 & $0.1,0.2$ & 0.002 \\
\hline In gravida $2+(n 695)$ & -0.0004 & $-0.04,0.04$ & 0.86 \\
\hline \multicolumn{4}{|l|}{ Gravidity†§ } \\
\hline Gravida $2+(n 695)$ & -0.6 & $-1 \cdot 0,-0.1$ & 0.02 \\
\hline Twin pregnancy $(n 12) \dagger$ & $-1 \cdot 8$ & $-3.4,-0.2$ & 0.03 \\
\hline $\begin{array}{l}\text { HIV load } \\
\quad\left(\log _{10}(1+\mathrm{geq} / \mathrm{ml})\right) \\
\quad(n 360) \|\end{array}$ & -0.1 & $-0.2,-0.003$ & 0.04 \\
\hline
\end{tabular}

${ }^{*} R^{2} 0.07$, intercept $40.9(95 \% \mathrm{Cl} 40.3,41.6)$ weeks. Variables assessed were season of birth, maternal height and arm muscle and fat area, age, gravidity, multiple pregnancies, infant sex, maternal malaria, and HIV status or viral load. Gestational age at inclusion was adjusted for (not shown).

t Reference categories were late rainy season, arm fat area $>20 \mathrm{~cm}^{2}$, gravida 1 , singletons.

¥The effect of age was significantly different between gravidae 1 and $2+$ (interaction, $P=0.005$ ).

$\S$ The effect of gravidity estimated at mean age 24 years, using gravida 1 as reference category.

II Maternal HIV load expressed as genome equivalents $(\mathrm{geq} / \mathrm{ml})$ and $\log _{10}(1+\mathrm{geq} / \mathrm{ml})$-transformed. HIV status was indeterminate in twenty-one women. not a predictor $(0.04(95 \% \mathrm{CI}-0.32,0.40) ; P=0.83)$ of gestation length, nor was maternal height, arm muscle area, and malaria and $\mathrm{Hb}$.

Maternal HIV load was a predictor of gestation length. Using dummy variables based on viral load categories $\left(<3,3-4,4-5\right.$ and $\left.>5 \log _{10}(\mathrm{geq} / \mathrm{ml})\right)$, none was associated with gestation length $(P>0 \cdot 07)$, but the regression coefficients decreased linearly, i.e. $-0.11,-0.27,-0.49$ and -0.75 (linear trend, $P=0.02$ ). In the model presented in Table 4, the effect of viral load as a continuous variable is estimated, after $\log (1+\mathrm{geq} / \mathrm{ml})$ transformation. The regression coefficient of $-0 \cdot 1$ reflects the decline in gestation length (weeks) per log increase in HIV load. The intercept of the model (Table 4) was 40.9 weeks, which is the mean gestation length among HIV-uninfected primigravidae at age 24 years, with greater than $20 \mathrm{~cm}^{2}$ arm fat area, delivering singleton babies in the late rainy season.

A similar model was developed in logistic regression using preterm delivery as the dependent variable

Table 5. Predictors of preterm delivery ( $<37$ weeks) in 1106 infants* (Odds ratios (OR) and $95 \%$ confidence intervals)

\begin{tabular}{|c|c|c|c|}
\hline Variables & OR & $95 \% \mathrm{Cl}$ & $P$ \\
\hline \multicolumn{4}{|l|}{ Season of birth $†$} \\
\hline Early dry (n 274) & $2 \cdot 9$ & $1 \cdot 65,5 \cdot 2$ & $<0.00001$ \\
\hline Late dry ( $n$ 379) & 0.94 & $0.51,1.72$ & 0.83 \\
\hline Early rain (n 291) & $1 \cdot 38$ & $0.75,2.52$ & $0 \cdot 30$ \\
\hline \multicolumn{4}{|l|}{ Arm fat area $\left(\mathrm{cm}^{2}\right) \dagger$} \\
\hline$<10(n 52)$ & $4 \cdot 16$ & $2 \cdot 13,8 \cdot 12$ & 0.00005 \\
\hline $10-20(n 585)$ & 1.44 & $1.001,2.08$ & 0.05 \\
\hline \multicolumn{4}{|l|}{ Age (years)‡ } \\
\hline In gravida 1 (n 411) & 0.84 & $0.76,0.94$ & 0.002 \\
\hline In gravida $2+(n 695)$ & 1.02 & $0.98,1.06$ & 0.40 \\
\hline Gravida $2+(n$ 695) †£ & 1.90 & $1.06,3.41$ & 0.03 \\
\hline Twin pregnancies $(n$ 12)† & 3.50 & $0.97,12.61$ & 0.06 \\
\hline $\begin{array}{l}\text { HIV load }\left(\log _{10}(1+\text { geq } / \mathrm{ml})\right) \\
\quad(n \text { 360) } \|\end{array}$ & 1.48 & $1 \cdot 04,2 \cdot 11$ & 0.03 \\
\hline
\end{tabular}

*Nagelkerke $R^{2}$ 0.11. Variables assessed were season, maternal arm muscle and fat area, age, gravidity, multiple pregnancies, infant sex, malaria parasitaemia, HIV status and viral load. Gestational age at inclusion was adjusted for.

†Reference categories were late rainy season, arm fat area $>20 \mathrm{~cm}^{2}$, gravida 1 , singletons.

$\ddagger$ The effect of age was significantly different between gravidae 1 and $2+$ (interaction, $P=0.006$ ).

$\S$ The effect of gravidity was estimated at age 24 years.

\| Maternal HIV load expressed as genome equivalents $(\mathrm{geq} / \mathrm{ml})$ and $\log _{10}(1+\mathrm{geq} / \mathrm{ml})$-transformed. HIV status was indeterminate in twenty-one women. 
Table 6. Predictors of birth weight $(\mathrm{g})$ in 1106 infants $^{*}$ (Regression coefficients (B) and 95\% confidence intervals)

\begin{tabular}{|c|c|c|c|}
\hline Variables & B & $95 \% \mathrm{Cl}$ & $P$ \\
\hline \multicolumn{4}{|l|}{ Season of birth $\dagger$} \\
\hline Early dry (n 274) & -114 & $-183,-46$ & 0.001 \\
\hline Early rainy $(n 196)$ & -23 & $-90,44$ & 0.51 \\
\hline Late rainy ( $n 158)$ & -78 & $-160,1$ & 0.06 \\
\hline Height $(\mathrm{cm}) \ddagger$ & 12 & 8,17 & $<0.00001$ \\
\hline \multicolumn{4}{|l|}{ Arm fat area $\left(\mathrm{cm}^{2}\right) \dagger$} \\
\hline $\begin{array}{l}<10(n 52) \\
10-20(n 585)\end{array}$ & $\begin{array}{r}-206 \\
-77\end{array}$ & $\begin{array}{l}-334,-79 \\
-133,-22\end{array}$ & $\begin{array}{l}0.002 \\
0.006\end{array}$ \\
\hline \multicolumn{4}{|l|}{ Gravidity† } \\
\hline Gravida 1 (n 411) & -204 & $-269,-140$ & $<0.00001$ \\
\hline Gravida 2 (n 695) & -128 & $-195,-61$ & 0.0003 \\
\hline Twin pregnancy $(n 12) \dagger$ & -539 & $-789,-288$ & 0.00002 \\
\hline Female sex $(n$ 503) $\dagger$ & -123 & $-176,-70$ & $<0.00001$ \\
\hline \multicolumn{4}{|c|}{ HIV load $\left(\log _{10}(1+\right.$ geq $\left./ \mathrm{ml})\right) \dagger \S$} \\
\hline$<3(n 53)$ & -40 & $-164,84$ & 0.52 \\
\hline $3-4(n$ 143) & -89 & $-169,-2$ & 0.03 \\
\hline $4-5(n 135)$ & -128 & $-210,-46$ & 0.002 \\
\hline $5+(n 29)$ & -181 & $-345,-17$ & 0.03 \\
\hline
\end{tabular}

* $R^{2} 0.14$, intercept $3331(95 \% \mathrm{Cl} 3261,3400) \mathrm{g}, n$ 1105. Variables assessed were season of birth, maternal height and arm muscle and fat area, age, gravidity, multiple pregnancies, infant sex, maternal HIV status or viral load.

† Reference categories were: late dry season, arm fat area $>20 \mathrm{~cm}^{2}$, gravida $3+$, singletons, male infant sex, HIV uninfected.

$\ddagger$ Heights were subtracted from the mean height of $161 \mathrm{~cm}$.

$\S$ Viral load expressed as genome equivalents $(\mathrm{geq} / \mathrm{ml})$ and $\log _{10}(1+$ $\mathrm{geq} / \mathrm{ml}$ )-transformed. Linear trend, $P=0.0003$. HIV status was indeterminate in twenty-one women.

(Table 5). Early dry season of birth was associated with a three times increased risk of preterm delivery, and arm fat area $<10 \mathrm{~cm}^{2}$ with a four times increased risk. In primagravidae, the risk of preterm delivery decreased with increasing age, whereas this was not the case in gravidae $2+$ (interaction, $P=0.006$ ), resulting in an almost

Table 7. Predictors of birth weight $<2500 \mathrm{~g}$ in 1106 infants $^{*}$ (Odds ratios (OR) and $95 \%$ confidence intervals)

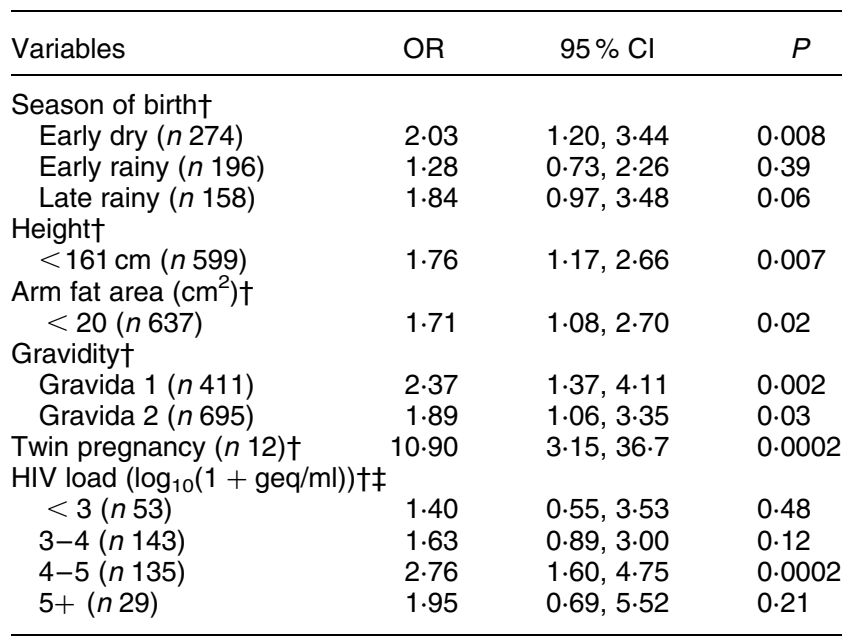

*Nagelkerke $R^{2}$ 0.11. Variables assessed were season, maternal arm muscle and fat area, age, gravidity, multiple pregnancies, infant sex, HIV status and viral load.

† Reference categories were late dry season, height $>161 \mathrm{~cm}$, arm fat area $>20 \mathrm{~cm}^{2}$, gravida $3+$, singletons, HIV uninfected.

$\ddagger$ Viral load expressed as genome equivalents (geq/ml) and $\log _{10}(1+$ geq $/ \mathrm{ml}$ )-transformed. Linear trend, $P=0.0004$. HIV status was indeterminate in twenty-one women.
Table 8. Predictors of birth length $(\mathrm{cm})$ in 1106 infants $^{*}$ (Regression coefficients (B) and $95 \%$ confidence intervals)

\begin{tabular}{lccc}
\hline Variables & $\mathrm{B}$ & $95 \% \mathrm{Cl}$ & $P$ \\
\hline Height $(\mathrm{cm}) \dagger$ & 0.05 & $0.02,0.07$ & 0.0004 \\
Arm fat area $\left(\mathrm{cm}^{2}\right) \ddagger$ & & & \\
$\quad<10(n$ 47) & -0.95 & $-1.57,-0.12$ & 0.02 \\
$\quad 10-20(n 511)$ & -0.35 & $-0.66,-0.04$ & 0.03 \\
Gravidity $\ddagger$ & & & \\
$\quad$ Gravida 1 $(n$ 358) & -0.40 & $-0.76,-0.03$ & 0.04 \\
$\quad$ Gravida 2 $(n$ 291) & -0.29 & $-0.66,0.10$ & 0.14 \\
Twin pregnancy $(n 9) \ddagger$ & -2.79 & $-4.35,-1.23$ & 0.0005 \\
Female sex $(n$ 452) $\ddagger$ & -0.57 & $-0.87,-0.26$ & 0.0003 \\
HIV infection $(n 314) \ddagger$ & -0.52 & $-0.84,-0.19$ & 0.002
\end{tabular}

${ }^{\star} R^{2} 0.07$, intercept $49.6(95 \% \mathrm{Cl} 49.2,49.9) \mathrm{cm}, n$ 977. Variables assessed were season, maternal height and arm muscle and fat area, age, gravidity, multiple pregnancies, infant sex, malaria parasitaemia, HIV status or viral load.

† Height was subtracted from the mean of $161 \mathrm{~cm}$.

$\ddagger$ Reference categories were arm fat area $>20 \mathrm{~cm}^{2}$, gravida $3+$, singletons, male infant sex, HIV uninfected.

twice as high risk in gravidae $2+$ among 24-year-old women. Maternal HIV load increased the risk of preterm delivery by $48 \%$ per log increase.

\section{Birth weight}

Compared with the late dry season, birth weights were 78 and $114 \mathrm{~g}$ lower in the late rainy and early dry seasons, respectively. Maternal height was a strong predictor of birth weight, in that birth weight increased by $12 \mathrm{~g}$ per $\mathrm{cm}$ increase in height (Table 6). If assessed using dummy variables based on quintiles and the upper quintile as reference, then birth weight was found to be 163, 127, 83 and $22 \mathrm{~g}$ lower in the four lower quintiles (data not shown). Arm fat, but not muscle, area was a positive predictor of birth weight. Infants of mothers with arm fat areas $<10 \mathrm{~cm}^{2}$ and between 10 and $20 \mathrm{~cm}^{2}$ had 206 and $77 \mathrm{~g}$ lower weights, respectively, than those of mothers with arm fat areas $>20 \mathrm{~cm}^{2}$.

In contrast with the case for gestation length, gravidity was an independent predictor of birth weight, whereas age was not a predictor (interaction, $P=0 \cdot 18$ ). Thus, infants of gravidae 1 and 2 had 204 and $128 \mathrm{~g}$, respectively, lower mean birth weights than infants of gravidae $3+$. Twin births were associated with $539 \mathrm{~g}$ lower birth weights, and female sex was associated with $123 \mathrm{~g}$ lower birth weight.

While a positive HIV status of the mother was associated with a $110(95 \%$ CI 40, 160) g $(P=0.0004)$ lower mean birth weight of her child, birth weight declined with increasing viral load; viral loads $<3,3-4,4-5$ and $>5 \log _{10}(\mathrm{geq} / \mathrm{ml})$ were associated with $40,89,128$ and $181 \mathrm{~g}$ lower birth weights compared with infants of uninfected mothers. It should be noted that the effects of high HIV load were underestimated with arm fat area in the model. Without low arm fat area in the model, then the effects of the two upper categories would be estimated at 143 and $207 \mathrm{~g}$.

Maternal age, arm muscle area, $\mathrm{Hb}$ and malaria parasitaemia were neither predictors nor confounders of birth weight. The intercept of the model shown in Table 6 was $3331 \mathrm{~g}$, reflecting the mean birth weight among 
$161 \mathrm{~cm}$ tall, HIV-uninfected, gravidae $3+$ delivering male singleton babies after conceiving in the late dry season. Including gestation length (regression coefficient (B) $=0.045(95 \%$ CI $0.035,0.054) ; P<0.00001)$ in the model increased adjusted $R^{2}$ from 0.14 to 0.22 . The effect of early dry season disappeared, as its effect apparently was mediated through gestation length. All other predictors remained significant, although the effects of arm fat area, multiple pregnancies and HIV infection slightly declined.

The same variables were predictors of birth weight $<2500$ g (Table 7), with the exception that female sex was not significant (odds ratio 1.32 (95\% CI $0.87,1.99)$ ). As expected, since gestation was longer in primigravidae, the effect of gravida 1 increased when gestation length was controlled for (not shown).

\section{Birth length and head circumference}

Height, arm fat area, gravidity, multiple pregnancy, female sex and HIV infection were predictors of birth length (Table 8), whereas season was not. Furthermore, the effect of HIV infection did not increase with HIV viral load. In contrast, HIV infection was not a predictor of birth head circumference $(-0.09$ (95\% CI $-0.32,0.14) ; P=0.43)$. Neonates of gravidae 1-2 had a 0.30 (95\% CI - 0.07, $-0.53) \mathrm{cm}$ lower head circumference than gravidae $3+$, but in contrast with weight and length, there was no difference between gravidae 1 and $2(-0.29 v .-0.32 \mathrm{~cm})$. Arm fat area $<20 \mathrm{~cm}^{2}$ was a predictor of head circumference, but only marginally significant.

\section{Discussion}

We have previously reported, based on data from our study, that a daily multimicronutrient supplement increases gestation length and birth weight, independently of season, gravidity, anaemia and infant sex (Friis et al. 2004). In the present paper we report the effect of other independent predictors. Height was a positive predictor of birth weight, while early dry season of birth, primigravidity, twin pregnancy, female infant sex, low maternal body fat mass and HIV load were all negative predictors of birth size. Controlling for gestation length explained the effect of season, but had only little effect on the other predictors, suggesting that their effects are mediated by fetal growth.

\section{Season, obstetric history and anthropometry}

Birth in the early dry season was a strong determinant of shorter gestation, which was accompanied by a lower birth weight. It is not clear which correlates of early dry season explain the shorter gestation. In The Gambia, a 2-300 g birth-weight deficit was seen in the wet season, which was preceded by both malarial morbidity, shortage of food, as well as hard physical work (Prentice et al. 1987). In Zimbabwe, the early dry season follows the harvest season and precedes the planting season, so it is neither characterised by food shortage nor hard physical work. It is the coldest time of the year, especially in Harare given the high altitude.
Malaria infection is a major cause of both premature delivery and intra-uterine growth retardation in many developing countries (Steketee, 2003), but was not endemic in the present study population. Data from the Dutch famine have convincingly shown that maternal malnutrition in the third trimester, but not earlier in gestation, reduces birth weight (Lumey, 1998). However, the differences between seasons with regard to food intake in this urban population is considered to be modest. Besides, neither maternal body composition nor micronutrient status explained the effect of season.

Gestation length increased with maternal age, but only in primigravidae. This led to a 0.5 week longer gestation in primigravidae compared with gravidae $2+$ at age 24 years, and almost 2 weeks longer gestation among women in their early thirties, a difference that is in accord with lay knowledge that primigravidae often deliver after term. In contrast, the effects of gravidity on birth weight were independent of age. Thus, despite their longer gestation, primigravidae have offspring with $204 \mathrm{~g}$ lower mean birth weights than gravidae $3+$.

Maternal height was a predictor of birth weight, but not of gestation length. Since maternal heights were similar to that of US women (Hediger et al. 1994), and effects were seen across the whole range of heights, it is probably due to genetic disposition rather than maternal stunting. Low maternal arm fat area, a proxy of body fat mass, was associated with shorter gestation and lower birth weight. The low arm fat area may reflect a low pre-pregnancy body fat mass, as well as inadequate deposition of fat during pregnancy. The finding is in accordance with research that found pre-pregnancy body composition (Neggers \& Goldenberg, 2003), as well as pregnancy skinfold thickness (Neggers et al. 1992; Hediger et al. 1994) and maternal fat intake (Rao et al. 2001), to be positively associated with birth weight. We found a threshold effect, as there were only effects below the population mean of $20 \mathrm{~cm}^{2}$, and this may explain why no relationship was found in studies from affluent populations (LanghoffRoos et al. 1987).

The sexual dimorphism in man with regard to fat stores is unique (Norgan, 1997), and the larger body fat mass in women seems to play a critical role in reproduction. Fertility is reduced among women with a low body fat mass compared with those with a normal fat mass (Zaadstra et al. 1993). This is advantageous, as energy is needed to sustain the growing fetus. In addition to the requirement for adequate pre-pregnancy fat stores, additional fat is deposited during pregnancy to further sustain the fetus during the latter part of pregnancy and the offspring during lactation (Institute of Medicine, 1990). It is generally assumed that the increasing body fat mass in women of reproductive age is due to postpartum fat retention, i.e. inadequate postpartum metabolisation of fat deposited during pregnancy. However, we have recently suggested that it is due to increased fat deposition with age, precipitated by the first pregnancy, rather than the cumulative retention of pregnancy weight gains (Friis et al. 2002a). It may be advantageous to have a small baby at the end of the first pregnancy, where the birth canal is narrower. If the mother then starts depositing fat after the first 
pregnancy, this may result in increased fertility as well as longer gestation and higher birth weight of subsequent infants, where this is associated with increased infant survival without the same risk of obstructed labour (Zaadstra et al. 1993). In fact, the duration of labour is considerable longer in primi- compared with multiparous women, despite the higher birth weight in the latter.

\section{HIV infection}

It is well documented that maternal HIV infection is a risk factor of preterm delivery and intra-uterine growth retardation (Castetbon et al. 1999; Ayisi et al. 2003), in particular if symptomatic (Dreyfuss et al. 2001). Pregnant women with HIV infection usually have asymptomatic infection with relatively low viral loads, probably because advancing infection reduces fertility and increases fetal loss (Gray et al. 1998; Glynn et al. 2000). Nevertheless, we found that birth weight declined with increasing viral load. Gestation length also declined with increasing HIV load, similar to what was reported by O'Shea et al. (1998). However, the effect on gestation length did not explain the effect on birth weight. Women with viral load $>5 \log$ had infants with birth weights almost $200 \mathrm{~g}$ lower than uninfected women. Part of the effect of HIV on birth weight was mediated by effects on maternal body fat mass. Since this was not due to an acute-phase response (data not shown) it may be that increased energy intake during pregnancy will prevent the effect of HIV on birth weight.

\section{Conclusion}

The high prevalence of low birth weight in developing countries is due to a complex of determinants. Low maternal body fat mass, probably due to both low pre-pregnancy fat stores and inadequate deposition during pregnancy, is preventable and hence of greatest importance.

\section{Acknowledgements}

We thank the women and staff at the EOMH for their participation and cooperation; the City Health Council, Harare and the staff at the Blair Research Laboratory for assistance in conducting the present study; the Secretary for Health, Zimbabwe, for permission to publish. The present study was supported by the Council for Development Research, Danish International Development Assistance and the Danish Council for Medical Research (to H. F.), Southampton Insurance, Zimbabwe, Foundation of 1870 , BASF Health and Nutrition, the Hørslev Foundation, the Dagmar Marshall Foundation, the Sophus Jacobsens Foundation and the Lily Benthine Lunds Foundation.

\section{References}

Ashworth A (1998) Effects of intrauterine growth retardation on mortality and morbidity in infants and young children. Eur $J$ Clin Nutr 52, Suppl. 1, S34-S41.

Ayisi JG, van Eijk AM, ter Kuile FO, Kolczak MS, Otieno JA, Misore AO, Kager PA, Steketee RW \& Nahlen BL (2003) The effect of dual infection with HIV and malaria on pregnancy outcome in western Kenya. AIDS 17, 585-594.
Barker DJ, Forsen T, Uutela A, Osmond C \& Eriksson JG (2001) Size at birth and resilience to effects of poor living conditions in adult life: longitudinal study. $B M J \mathbf{3 2 3}$, $1273-1276$.

Castetbon K, Ladner J, Leroy V, Chauliac M, Karita E, De Clercq A, Van de Perre P \& Dabis F (1999) Low birthweight in infants born to African HIV-infected women: relationship with maternal body weight during pregnancy: Pregnancy and HIV Study Group (EGE). J Trop Pediatr 45, 152-157.

de Onis M, Blossner M \& Villar J (1998) Levels and patterns of intrauterine growth retardation in developing countries. Eur $J$ Clin Nutr 52, Suppl. 1, S5-S15.

Dreyfuss ML, Msamanga GI, Spiegelman D, Hunter DJ, Urassa EJ, Hertzmark E \& Fawzi WW (2001) Determinants of low birth weight among HIV-infected pregnant women in Tanzania. Am J Clin Nutr 74, 814-826.

Friis H, Gomo E, Kaestel P, Nyazema N, Ndhlovu P \& Michaelsen KF (2002a) Does the first pregnancy precipitate age-related fat deposition? Int J Obes 26, 1274-1276.

Friis H, Gomo E, Koestel P, Ndhlovu P, Nyazema N, Krarup H \& Michaelsen KF (2001a) HIV and other predictors of serum beta-carotene and retinol in pregnancy: a cross-sectional study in Zimbabwe. Am J Clin Nutr 73, 1058-1065.

Friis H, Gomo E, Koestel P, Ndhlovu P, Nyazema N, Krarup H \& Michaelsen KF (2001b) HIV and other predictors of serum folate, serum ferritin, and hemoglobin in pregnancy: a crosssectional study in Zimbabwe. Am J Clin Nutr 73, 1066-1073.

Friis H, Gomo E, Nyazema N, Ndhlovu P, Kaestel P, Krarup H \& Michaelsen KF (2002b) HIV-1 viral load and elevated serum alpha(1)-antichymotrypsin are independent predictors of body composition in pregnant Zimbabwean women. J Nutr 132, 3747-3753.

Friis H, Gomo E, Nyazema N, Ndhlovu P, Krarup H, Kaestel P \& Michaelsen KF (2004) Effects of multimicronutrient supplementation on gestation length and birth size: a randomized, placebo-controlled, double-blind effectiveness trial in Zimbabwe. Am J Clin Nutr 80, 178-184.

Friis H, Gomo E, Nyazema N, Ndhlovu P, Krarup H \& Madsen PH (2003) Fe, haptoglobin phenotype and HIV-1 viral load: a cross-sectional study among pregnant Zimbabwean women. J Acquir Immune Defic Syndr 33, 74-81.

Glynn JR, Buve A, Carael M, Kahindo M, Macauley IB, Musonda RM, Jungmann E, Tembo F \& Zekeng L (2000) Decreased fertility among HIV-1-infected women attending antenatal clinics in three African cities. J Acquir Immune Defic Syndr 25, 345-352.

Gray RH, Wawer MJ, Serwadda D, et al. (1998) Population-based study of fertility in women with HIV-1 infection in Uganda. Lancet 351, 98-103.

Hediger ML, Scholl TO, Schall JI, Healey MF \& Fischer RL (1994) Changes in maternal upper arm fat stores are predictors of variation in infant birth weight. J Nutr 124, 24-30.

Institute of Medicine (1990) Body composition changes during pregnancy. In Nutrition During Pregnancy, pp. 121-136 Washington, DC: National Academy Press.

Kramer MS (2003) The epidemiology of adverse pregnancy outcomes: an overview. J Nutr 133, 1592S-1596S.

Krarup HB, Drewes AM \& Madsen PH (1998) A quantitative HCV-PCR test for routine diagnostics. Scand J Clin Lab Invest 58, 415-422.

Langhoff-Roos J, Lindmark G \& Gebre-Medhin M (1987) Maternal fat stores and fat accretion during pregnancy in relation to infant birthweight. Br J Obstet Gynaecol 94, 1170-1177.

Lumey LH (1998) Reproductive outcomes in women prenatally exposed to undernutrition: a review of findings from the Dutch famine birth cohort. Proc Nutr Soc 57, $129-135$. 
McDade TW, Beck MA, Kuzawa C \& Adair LS (2001) Prenatal undernutrition, postnatal environments, and antibody response to vaccination in adolescence. Am J Clin Nutr 74, $543-548$.

Moore SE, Cole TJ, Collinson AC, Poskitt EM, McGregor IA \& Prentice AM (1999) Prenatal or early postnatal events predict infectious deaths in young adulthood in rural Africa. Int $J$ Epidemiol 28, 1088-1095.

Neggers Y \& Goldenberg RL (2003) Some thoughts on body mass index, micronutrient intakes and pregnancy outcome. J Nutr 133, 1737S-1740S.

Neggers Y, Goldenberg RL, Cliver SP, Hoffman HJ \& Cutter GR (1992) Usefulness of various maternal skinfold measurements for predicting newborn birth weight. J Am Diet Assoc 92, $1393-1394$.

Norgan NG (1997) The beneficial effects of body fat and adipose tissue in humans. Int J Obes Relat Metab Disord 21, 738-746.
O'Shea S, Newell ML, Dunn DT, et al. (1998) Maternal viral load, CD4 cell count and vertical transmission of HIV-1. J Med Virol 54, 113-117.

Prentice AM, Cole TJ, Foord FA, Lamb WH \& Whitehead RG (1987) Increased birthweight after prenatal dietary supplementation of rural African women. Am J Clin Nutr 46, 912-925.

Rao S, Yajnik CS, Kanade A, et al. (2001) Intake of micronutrient-rich foods in rural Indian mothers is associated with the size of their babies at birth: Pune Maternal Nutrition Study. J Nutr 131, 1217-1224.

Steketee RW (2003) Pregnancy, nutrition and parasitic diseases. $J$ Nutr 133, 1661S-1667S.

Zaadstra BM, Seidell JC, van Noord PA, te Velde ER, Habbema JD, Vrieswijk \& Karbaat J (1993) Fat and female fecundity: prospective study of effect of body fat distribution on conception rates. BMJ 306, 484-487. 